\title{
Efficient Mathematical Model for Prestressing Cables and Its Implementation in Computer Analysis
}

\author{
Dr. Pushpa Pathote \\ Chameli Devi Group of Institutions, Indore
}

\begin{abstract}
Splines, which were invented by Schoenberg, constitute a smooth curve between given data points. They are widely used in computer-aided designs, geometric modeling, graphics, and aerodynamic designs. This paper gives a new technique for efficient mathematical modeling of prestressing cable using B-spline curve. In prestressed concrete structures, cable profile plays an important role in reducing tension from concrete. So far, this cable was modeled, as of parabolic shape but the actual cable profile is a smooth curve. A new approach has been used in this paper for efficient modeling of cable using B-spline. This gives various other added advantages, which is not possible by any other curve. This is implemented in finite element analysis of 9-node Lagrangian element for concrete and cable model by 3-node bar element. Based on vector calculus formulation reaction of the cable on the concrete is obtained and applied on finite element nodes. Effects of friction and cable stiffness are taken into accounts. A finite element software has been developed incorporating these features. Various prestressed concrete beams of different spans have been successfully analysed and validated. It is observed, this formulation is very powerful in accurate analysis of the prestressed concrete structures.
\end{abstract}

\section{Introduction}

A B-spline is a typical curve of the CAD philosophy. It models a smooth curve between the given ordinates. Most of the researchers have used this curve in shape optimization problems and first time cable geometry is being modeled as B-spline. If we have $\mathrm{N}+1$ control points $\mathrm{Pi}$, we can derive continuous function $\mathrm{P}(\mathrm{t})$ as-

$$
\mathrm{P}(\mathrm{t})=\Sigma \mathrm{P}_{\mathrm{i}} \cdot \mathrm{N}_{\mathrm{i}, \mathrm{k}}(\mathrm{t}) \quad 0<\mathrm{t}<\mathrm{n}-\mathrm{k}+2,2 \leq \mathrm{k}<\mathrm{n}
$$

Where

$$
\begin{array}{ll}
\mathrm{N}_{\mathrm{i}, 1}(\mathrm{t})= & 1 \\
& 0
\end{array} \quad\left\{\begin{array}{l}
\text { if } \mathrm{x}_{\mathrm{i}} \leq \mathrm{t} \leq \mathrm{x}_{\mathrm{i}+1} \\
\text { otherwise }
\end{array}\right.
$$

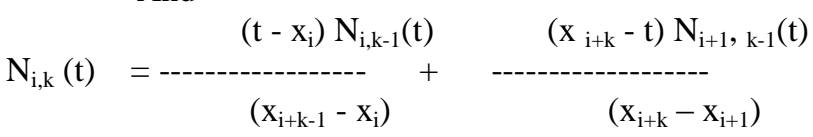

in this equation. $\mathrm{P}_{\mathrm{i}}$ 's are the $\mathrm{n}+1$ defining polygon vertices, $\mathrm{k}$ is the order of the $\mathrm{B}$-spline and $\mathrm{N}_{\mathrm{i}, \mathrm{k}}(\mathrm{t})$ is called the weighting function. $\mathrm{X}$ is the additional knot vector, which is used for $\mathrm{B}$-spline curves to account for the inherent added flexibility. A knot vector is simply a series of real integers $\mathrm{x}_{\mathrm{i}}$ such that $\mathrm{x}_{\mathrm{i}} \leq \mathrm{x}_{\mathrm{i}+1}$ for all $\mathrm{x}_{\mathrm{i}}$.

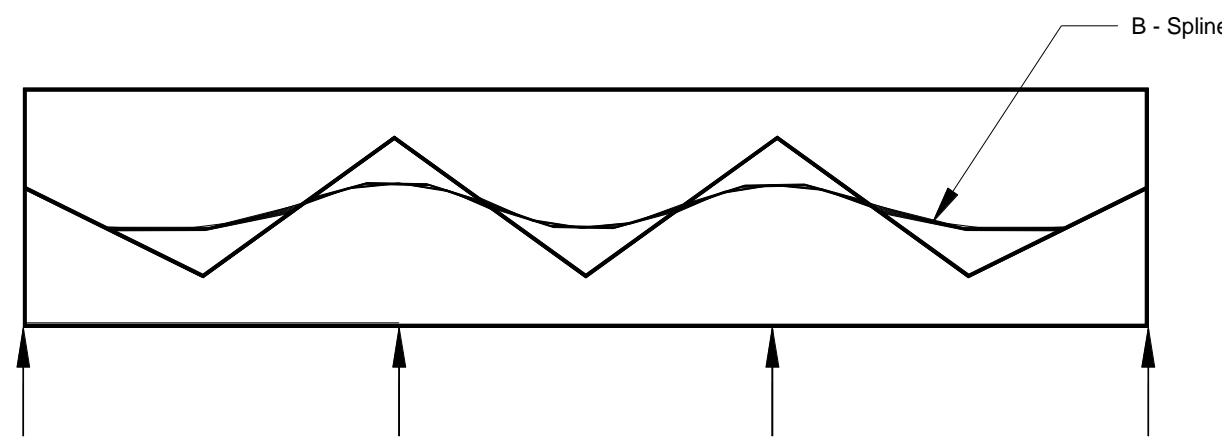

Fig.1: Cable profile as B-spline 
Advantages of B-spline curve are follows:

- Changes to a control point only affect the curve in that locality.

- Any number of points can be added without increasing the degree of the polynomial.

- As with Bezier curve adding multiple points at or near a single position draws the curve towards that position.

- B-spline lie in the convex hull of the control points.

\section{Levels of Continuity}

- $\mathrm{C}^{0}$ continuity: $\mathrm{C}^{0}$ continuity ensures that there are no gaps or breaks between a curve's beginning and ending points. The resulting curve is continuous at the join point (but not necessarily smooth).

- $\mathrm{C}^{1}$ continuity: $\mathrm{C}^{1}$ continuity between two curve segments requires a common tangent line at there joining point; $\mathrm{C}^{1}$ continuity also requires $\mathrm{C}^{0}$ continuity. The resulting curve is continuous and the derivatives of the two segments match at the join point.

- $\mathrm{C}^{2}$ continuity: $\mathrm{C}^{2}$ continuity requires that the two curves possess same curvature at there joint. The curve is continuous, the derivatives and the 2 nd derivatives match at the join point.

We would like a method that provides smooth continuity at the join points, like Hermite curves, but that uses data from a set of points like Bezier curves. Splines provide such a method, and provide $\mathrm{C}^{2}$ continuity.
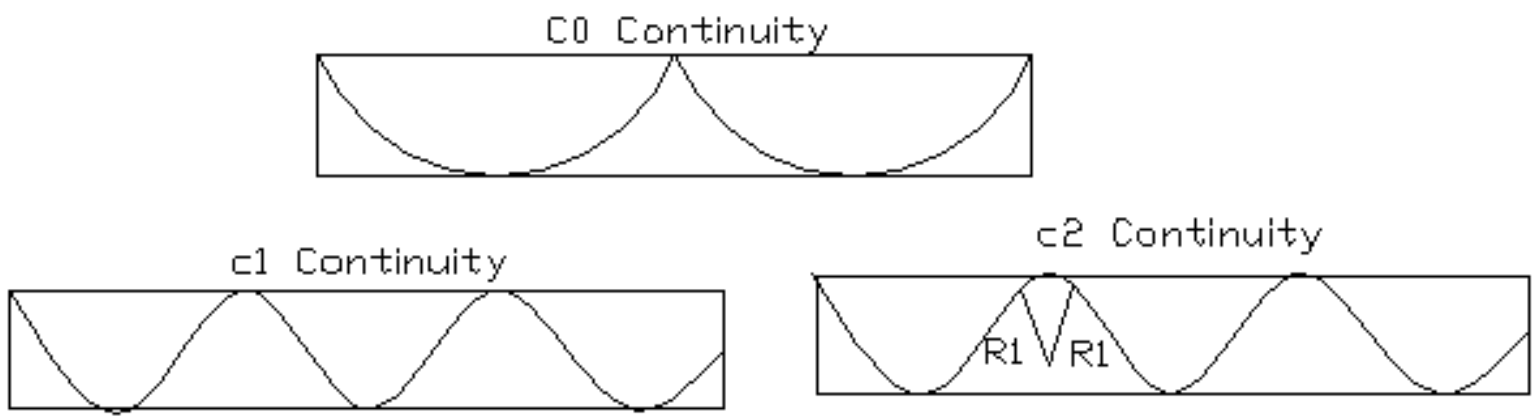

Fig.2 Levels of continuity

\section{Prestressed concrete}

Concrete is a stone like material, which is mixture of cement, sand, aggregate and waters. This concrete is hard, strong in compression and shear, brittle and weak in tension. Hence to strengthen the concrete in tension, steel bars (i.e. reinforcement) are provided in the tensile zone. Such concrete is known as reinforced cement concrete (RCC). In prestressed concrete high tensile strength steel bars are used which are called tendon. These tendons are already stressed before embedding in concrete by tensioning device to develop stresses of opposite nature. When member is loaded first these stresses are neutralized and then tendons get stressed to opposite nature of stresses to reduce or eliminate the tensile stresses, which control or eliminate cracking. In this way a prestressed concrete section is considerably stiffer than reinforced concrete section. In curved tendons, upward force is imposed on concrete, which may reduce or eliminate the downward deflection as well. These prestressed concrete structures are very useful:

- It is useful in construction in liquid retaining structure and nuclear containment structure where absolutely no leakage is acceptable.

- Railway sleepers

- Large span bridges

- High rise buildings

- Long span roofs etc.

In prestressed concrete, cable layout plays an important role in reducing tension from the concrete. Due to curvature, cable exerts forces on the concrete to counter balance the forces causing tension. Actual cable profile is a smooth curve passing through all the spans. 


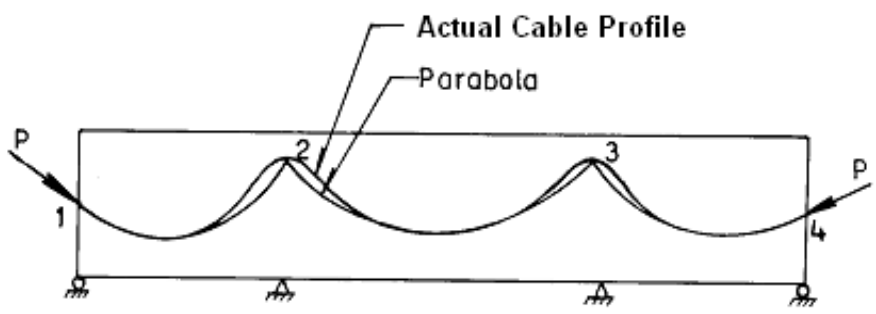

Fig.3: Cable profiles

So far, this cable was modeled, as of parabolic shape but the actual cable profile is a smooth curve. So a new approach has been used in this paper for efficient modeling of cable using B-spline. This gives various other added advantages, which is not possible by any other curve.

\section{FE Formulation}

In parabolic modeling curvature is constant due to which distribution of load will be constant everywhere therefore analysis for this model is cheap. Whereas in spline curve curvature is different at each point of the curve hence load distribution is not constant and hence analysis for this model needs some computational efforts. The FE modeling of the prestressed concrete beam is carried out using 9-node Langerangian element for concrete and 3-node bar elements for cable (fig.4).
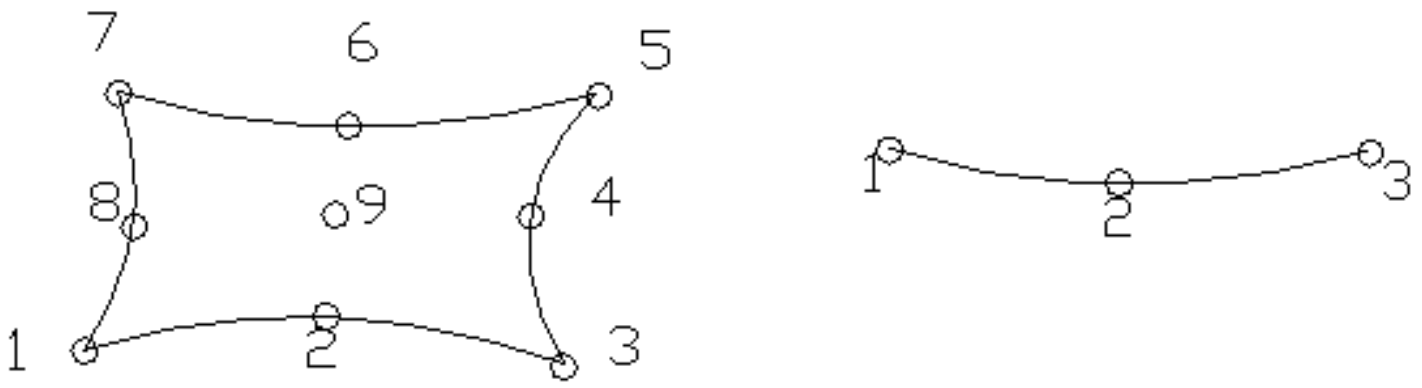

Fig.4: 9-node Langerangian element and 3-node curved bar element

\section{Modeling of the Pre-Stressing Cable}

Modeling of the prestressing cable in the finite element analysis of a prestressed concrete structure is a tedious process. Cable profile modeled by B-spline gives a very smooth shape fig.1. the cable is considered to be embedded in the concrete and there exists perfect bond between them. The shape functions of 3-node curved bar element is given by-

$N_{c 1}=\frac{(\rho-1) \rho}{2}, N_{c 2}=(1-\rho)(1+\rho), N_{c 3}=\frac{(\rho+1) \rho}{2}$

The global co-ordinates inside the curved bar element can be defined by-

$\bar{X}=\left(\begin{array}{l}x \\ y\end{array}\right)=\sum_{i=1}^{3}\left(\begin{array}{l}x \\ y\end{array}\right) N_{c i}=\sum_{i=1}^{3} X_{i} N_{c i}$

The tangent vector along $\rho$ axis for the cable is given by-

$\bar{T}=\sum_{i=1}^{3} X_{i} \frac{d N_{c i}}{d \rho}$

And the normal vector can be given by-

$\bar{N}=\frac{1}{|\bar{T}|^{2}}\left[\frac{d^{2} x}{d \rho^{2}}-\frac{a}{|\bar{T}|^{2}} \frac{d X}{d \rho}\right]$

where $a=\frac{d X}{d \rho} \cdot \frac{d^{2} X}{d \rho}$ 
is a dot product. Now the unit tangent and normal vectors can be given by -

$\bar{t}=\frac{\bar{T}}{|\bar{T}|}$ and $\bar{n}=\frac{\bar{N}}{|\bar{N}|}$

The curvature at any point on the curve can be given by-

$$
K=\frac{\left|\frac{d X}{d \rho} \times \frac{d^{2} X}{d \rho^{2}}\right|}{\left\{\left|\frac{d X}{d \rho}\right|^{2}\right\}^{\frac{3}{2}}}
$$

Numerator of (Eq.9) is a cross product. The radius of curvature $\mathrm{R}$ is given by

$$
\mathrm{R}=1 / \mathrm{K}
$$

Friction Loss:

The cable tension reduces along the length of cable due to friction between the cable and duct. The bar element is assumed to have two Gauss points GP1 \& GP2. The radius of curvature R, obtained above is eq.11 is utilized in the calculation of friction loss. Assume curvature between $1 \& 2$ and $2 \& 3$ equal to the curvature R1 \& $\mathrm{R} 2$. Let the length of the cable between 1-2 and 2-3 be approximated as-

$$
\begin{gathered}
\mathrm{L}_{1-2} \approx \sqrt{ }\left(\mathrm{x}_{1}-\mathrm{x}_{2}\right)^{2}+\left(\mathrm{y}_{1}-\mathrm{y}_{2}\right)^{2} \\
\mathrm{~L}_{2-3} \approx \sqrt{ }\left(\mathrm{x}_{2}-\mathrm{x}_{3}\right)^{2}+\left(\mathrm{y}_{2}-\mathrm{y}_{3}\right)^{2}
\end{gathered}
$$

The tension variation in the bar element can be expressed by isoparametric interpolation as$T_{n}=\sum_{i=1}^{3} T_{i} N_{c i}$

If the radius of curvature at GP1 and GP2 be $\mathrm{R}_{1}$ and $\mathrm{R}_{2}$ then tension at $2 \& 3$ after friction loss will be-

$$
\begin{gathered}
\mathrm{T}_{2}=\mathrm{T}_{1} \mathrm{e}^{\left(-\mu \alpha_{1}-\mathrm{KL}_{1-2}\right)^{\left(-\mu \alpha_{1-3}\right.}} \\
\mathrm{T}_{3}=\mathrm{T}_{2} \mathrm{e}_{2}^{\left(-\mu \alpha_{2-3}\right)}
\end{gathered}
$$

Where, $T_{1}=$ Tension at jacking end for first element. For subsequent elements $T_{1}$ will become $T_{3}$ of previous element.

$\alpha_{1}=\mathrm{L}_{1-2} / \mathrm{R}_{1}$

$$
\mathrm{K}=\text { wobble coefficient }
$$$$
\alpha_{2}=\mathrm{L}_{2-3} / \mathrm{R}_{2}
$$$$
\mu=\text { Coefficient of friction }
$$

In this way cable tension at different locations along cable profile can be obtained.

\section{Forces on concrete due to cable:}

The cable exerts normal and tangential forces on the concrete due to curvature and friction. These are expressed as-

$P_{t}=\frac{d T_{n}}{d X}=\frac{1}{|\bar{T}|} \frac{d T_{n}}{d \rho}$

$P_{n}=\frac{T_{n}}{R}$.

Where $\mathrm{Tn}$ is the tension in the cable and $\mathrm{T}$ is the tangent vector (eq.13).

The resultant of these is given by -

$$
\bar{P}=P_{t} \bar{t}+P_{n} \bar{n}
$$

Where $\overline{\mathrm{t}}$ and $\overline{\mathrm{n}}$ are unit tangent and normal vectors (eq.8, 9).

These loads can be transferred to concrete nodes, using the principle of virtual work. The equivalent nodal force vector for concrete element is expressed as-

$\left\{P_{L}\right\}=\int_{-1}^{1}[N]^{T}\{\bar{P}\}|\bar{T}| d \rho$ 
At end elements where cable is anchoraged, cable reaction acts as concentrated loads on the concrete. The anchorage end point forces can be transferred at the nodes in the ratio of shape function and are given by-

$$
\left\{\mathrm{P}_{\mathrm{A}}\right\}=[\mathrm{N}]^{\mathrm{T}}\left\{\mathrm{T}_{\text {end }}\right\}
$$
element.

Where, $\mathrm{T}_{\text {end }}$ is the cable tension at the end pints. [N] In Eq.18\&19 are the shape functions of nine-node

In calculation of Eq.19, local co-ordinates of the anchorage points are required for known global co-ordinates. This is calculated by Newton Raphson iterative method.

So, total load vector due to cable concrete interaction is obtained by-

$$
\left\{\mathrm{P}_{\mathrm{T}}\right\}=\left\{\mathrm{P}_{\mathrm{L}}\right\}+\left\{\mathrm{P}_{\mathrm{A}}\right\}
$$

This nodal load vector is applied on the structure along with live and dead load vectors to include prestressing effects.

\section{Computation of Local Co-ordinates $(\xi, \eta)$ :}

In above calculation local co-ordinates of known global co-ordinates are required. It is an inverse nonlinear problem, which is solved iteratively by Newton-Raphson method as follows. Let (x,y) is the global coordinate and $(\xi, \eta)$ be corresponding local co-ordinate then-

$\left.\left(\begin{array}{l}\xi \\ \eta\end{array}\right)_{i+1}=\left(\begin{array}{l}\xi \\ \eta\end{array}\right)_{i}-\left[\begin{array}{ll}\frac{\partial x}{\partial \xi} & \frac{\partial x}{\partial \eta} \\ \frac{\partial y}{\partial \xi} & \frac{\partial y}{\partial \eta}\end{array}\right]^{-1} \quad \begin{array}{l}x_{i+1}-x_{i} \\ y_{i+1}-y_{i}\end{array}\right)$.

in above equation inverse matrix is nothing but Jacobian matrix. $\left(\mathrm{x}_{\mathrm{i}+1}, \mathrm{y}_{\mathrm{i}+1}\right)$ is the computed value and $\left(\mathrm{x}_{\mathrm{i}}, \mathrm{y}_{\mathrm{i}}\right)$ are the known value. Initial value of $(\xi, \eta)$ are taken as zero. The computation is carried out iteratively till the difference of two consecutive value of $(\xi, \eta)$ becomes less than tolerance value. In this study this is taken as 0.001. This formulation has been incorporated in FORTRAN software named PRCON2D. Using this software following analysis are carried out:

(1) Single Span Prestressed Beam:

The beam has following properties:Point load at center $\mathrm{W}=2 \mathrm{KN}$,Prestressing force $\mathrm{P}=100 \mathrm{KN}$, Width, height and span $=100,200$ and $12000 \mathrm{~mm}$ respectively.

No. of elements and node $=30$ and 183 respectively, Young's Modulus and Poisson Ratio $=2 \times 10^{4} \mathrm{~N} / \mathrm{mm}^{2}$ and 0.3

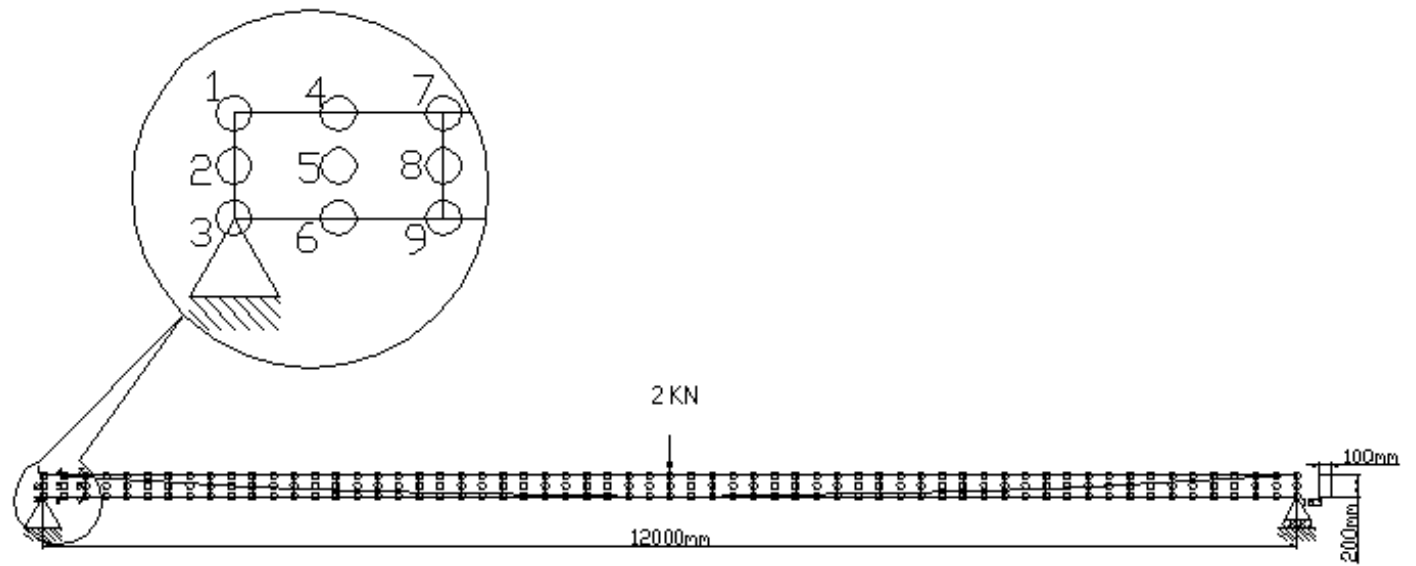

Fig.5 Single Span Beam

\begin{tabular}{|c|c|c|c|c|c|c|}
\hline \multirow{3}{*}{$\begin{array}{l}\text { Case } \rightarrow \\
\text { Stress at section } \\
\downarrow\end{array}$} & \multicolumn{4}{|c|}{ B- spline(without friction) } & \multicolumn{2}{|c|}{ B- spline (with friction) } \\
\hline & \multicolumn{2}{|c|}{ Top } & \multicolumn{2}{|c|}{ Bottom } & Top & Bottom \\
\hline & computer & Theory & computer & Theory & computer & computer \\
\hline Section 1-1 & -2.72 & -2.76 & -7.32 & -7.32 & -3.11 & -6.30 \\
\hline
\end{tabular}

Table 1: Stress in Mpa at mid span\

Stresses for this beam is given in the above table 1.Maximum deflection at center is $+30.40 \mathrm{~mm}$ and reduced prestressing force $\mathrm{P}^{\prime}$ due to friction at the other end is $87.8 \mathrm{KN}$. 
(2) Five Span Prestressed Concrete Beam: The beam has following properties:

Point loads at center of each $\operatorname{span} \mathrm{W} 1=\mathrm{W} 5=\mathrm{W} 3=50 \mathrm{KN}, \mathrm{W} 2=\mathrm{W} 4=100 \mathrm{KN}$

Prestressing force $\mathrm{P}=500 \mathrm{KN}$

Width, height and span $=250,500,8000 \mathrm{~mm}$ respectively.

No. of elements and node $=40,243$ respectively

Young's Modulus and Poisson Ratio $=2 \times 10^{4} \mathrm{~N} / \mathrm{mm}^{2}$ and 0.3

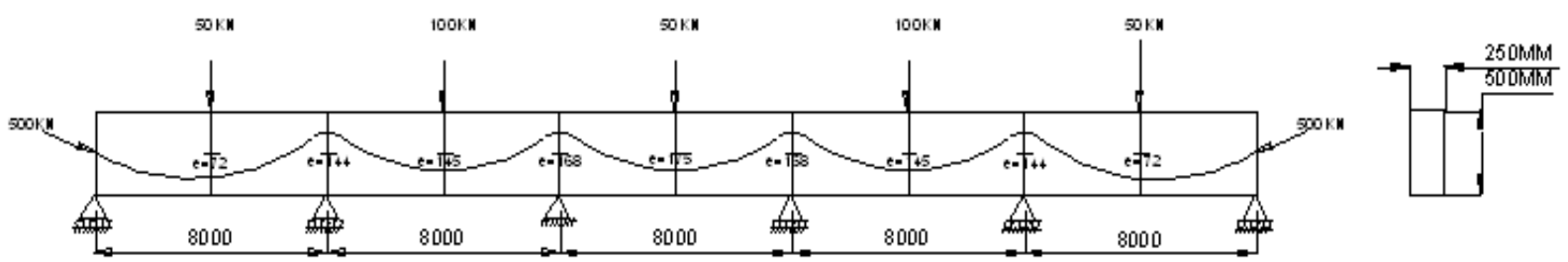

FIVE SPAN PRESTRESSED CONCRETE BE AM

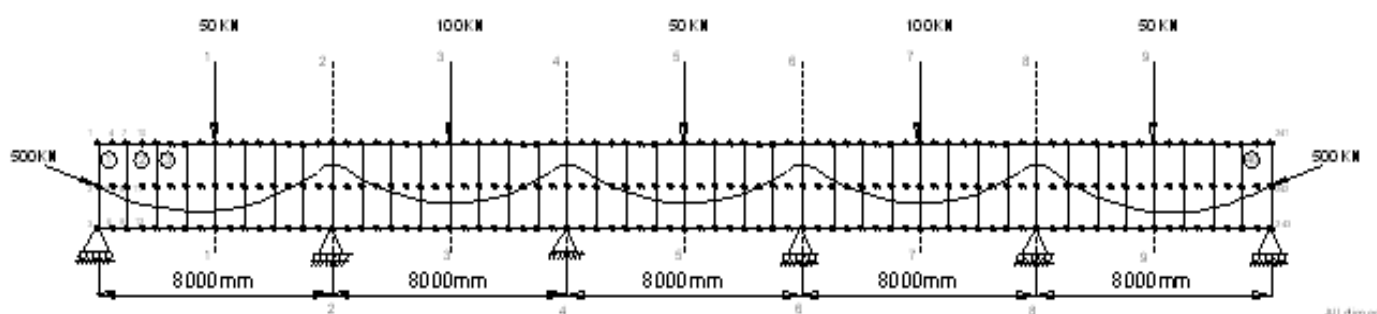

Fig: 6 Five Span Beam

For this beam, cable is modeled by B spline curve and stresses at different mid span is shown in table 2 and deflection is in table 3. Distributions of stresses at top and bottom profile are shown in fig.10 and 11 . It is observed that in case of without friction condition there is tension at one point whereas in with friction condition it is at five points. Hence friction plays significant role in reduction of tensile stress. Reduced prestressing force due to friction P' at the other end: $193 \mathrm{KN}$

Table 2: Stress at mid span and at supports

\begin{tabular}{|l|c|c|c|c|}
\hline \multirow{2}{*}{ Stress at section $\downarrow$} & B- spline(without friction) & B- spline (with friction) \\
\cline { 2 - 5 } & Top & Bottom & Top & Bottom \\
\hline Section 1-1 & -5.69 & -2.48 & -5.66 & -1.73 \\
\hline Section2-2 & -0.75 & -7.66 & 0.97 & -7.97 \\
\hline Section 3-3 & -8.11 & -0.29 & -8.80 & 2.42 \\
\hline Section 4-4 & -4.61 & -3.75 & -1.13 & -4.65 \\
\hline Section 5-5 & 1.27 & -9.47 & -0.24 & -4.91 \\
\hline Section 6-6 & -4.59 & -3.75 & 0.20 & -5.02 \\
\hline Section 7-7 & -8.10 & -0.26 & -9.55 & -8.06 \\
\hline Section 8-8 & -0.72 & -7.64 & 4.16 & 1.66 \\
\hline Section 9-9 & -5.66 & -2.46 & -5.24 & \\
\hline
\end{tabular}

Table 3: Deflection at middle of various locations:

\begin{tabular}{|l|c|c|}
\hline $\begin{array}{l}\text { Deflection } \rightarrow \\
\text { Section } \downarrow\end{array}$ & $\begin{array}{c}\text { Deflection (without friction) } \\
\delta(\mathrm{mm})\end{array}$ & $\begin{array}{c}\text { Deflection (with friction) } \\
\delta^{\prime}(\mathrm{mm})\end{array}$ \\
\hline Section 1-1 & -0.158 & -0.158 \\
\hline Section 3-3 & -2.41 & -3.56 \\
\hline Section 5-5 & +6.81 & +4.43 \\
\hline Section 7-7 & -2.43 & -5.20 \\
\hline Section 9-9 & -0.152 & -1.94 \\
\hline
\end{tabular}



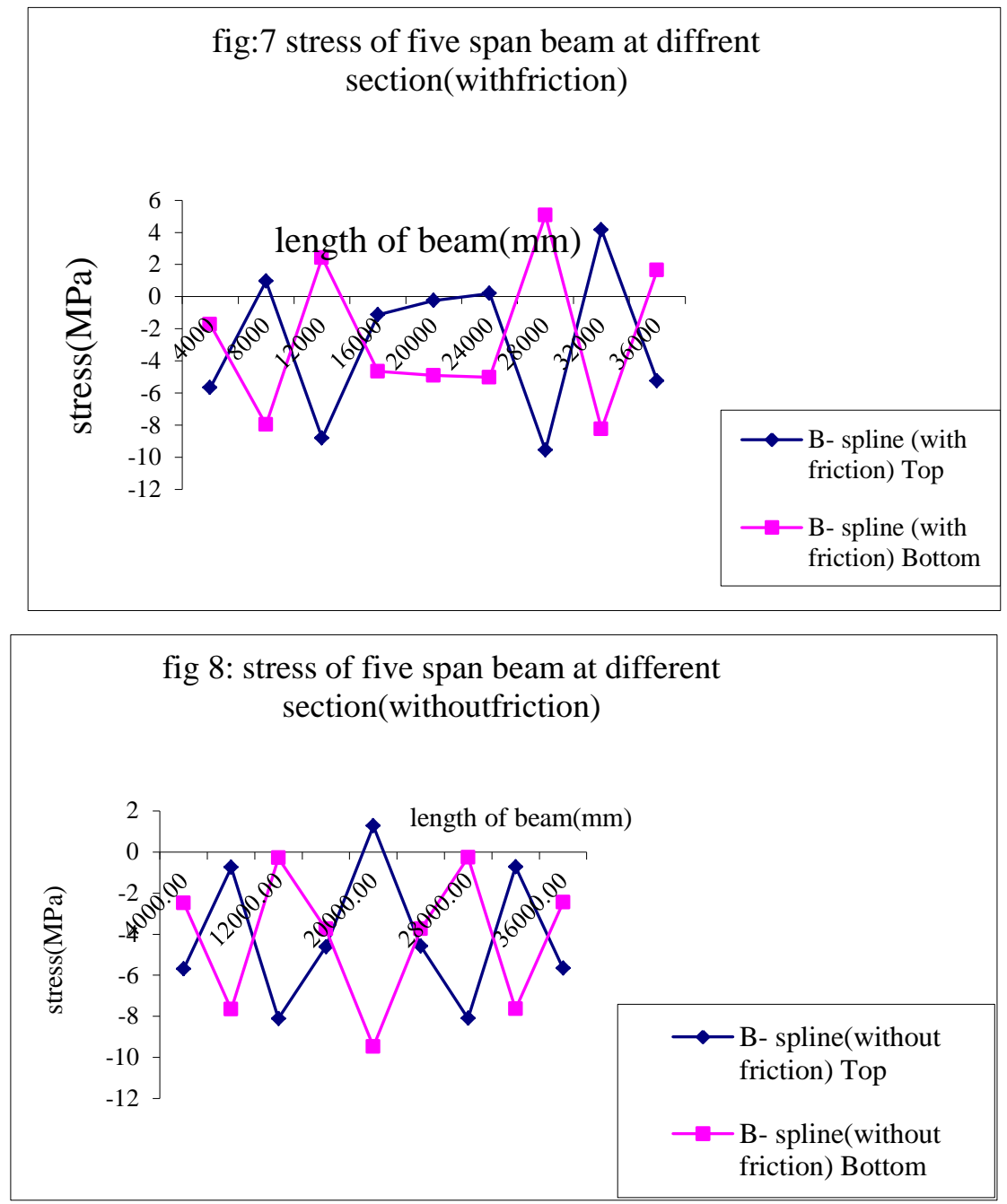

\section{Conclusions}

In this study a new mathematical finite element based approach has been proposed to analyze PC studies. It accounts friction and cable stiffness. Cable is modeled by B-spline curve and its interaction with concrete is obtained by vector calculus formulation .It overcomes the drawbacks of other models. Several PC beams are successfully analyzed. It is observed that this formulation is very powerful in accurate analysis of PC structures.

\section{Reference}

[1]. Bangesh M.Y.H. "Concrete and concrete structures: Numerical modeling and Application”, Elsevier, London (1989).

[2]. Gerald Farin, Curves and Surfaces for Computer Aided Geometric Design, Academic Press,(1988)

[3]. Jain M.K., S.R.K.Iyenger and R.K. Jain, "Numerical Methods Problem and solutions", New Age Publications, New Delhi, 166168.

[4]. Qing S.B. and Liu Ding Yuan, Computational Geometry - Curve and Surface Modeling, Academic Press, London(1989)

[5]. Rogers D.F., and Adams J.A., Mathematical Elements for Computers Graphics, Second Edition, McGraw Hill, New York, (1990)

[6]. Zienkiewicz,O.C., and Taylor, R.L., The Finite Element Method Vol.1\&2, Forth Edition,McGraw Hill Book Company, London, (1991)

\section{Acknowledgement:}

I am thankful to Dr. S.S. Pagey, Head of Mathematics Department, Institute for Excellence in Higher Education, Bhopal and Dr. K.K. Pathak, Scientist, Regional Research Laboratory, Bhopal for his invaluable guidance and encouragement in carrying out the present research work. 